\title{
Casuística de Carcinoma Epidermóide Cutâneo em bovinos do Campus Palotina da UFPR
}

\author{
Casuistry of Epidermoid Carcinomas in bovines from Campus Palotina-UFPR \\ Daniel Keller ${ }^{1}$, Miltom Rönnau², Marco Aurélio Gusmão \& Márcia Bersane Araújo de Medeiros Torres²
}

\begin{abstract}
RESUMO
Os carcinomas epidermóides são neoplasias malignas de células epiteliais comuns em todas as espécies e ocorre principalmente em áreas mais despigmentadas da pele, sendo a radiação ultravioleta provavelmente o estímulo carcinógeno mais importante para sua ocorrência. Neste trabalho, foram descritos 20 casos de carcinoma epidermóide em bovinos necropsiados no Laboratório de Patologia Veterinária da UFPR - Campus Palotina, no período de 1996 a 2007. Houve predomínio da raça Holandesa, com idade média de 5 anos e, nos 20 casos descritos, 8 apresentaram metástases. As neoplasias que envolviam o globo ocular apresentaram metástase em mais de $50 \%$ dos casos, principalmente para os pulmões e linfonodos regionais e, quando os tumores do dorso e da vulva ocorreram juntamente com o olho, apresentaram maior potencial metastático. A maioria dos carcinomas epidermóides eram bem diferenciados e as metástases provavelmente ocorreram devido ao longo tempo de evolução e invasão excessiva do tumor nos tecidos adjacentes.
\end{abstract}

Descritores: Carcinoma Epidermóide, Metástase, Neoplasias, Bovinos.

\begin{abstract}
The epidermoid carcinomas are malignant neoplasms from epitelial cells comuns in every species and occurs primarily in sites of piel more unnpigmented and the ultraviolet light is probably the stimulus carcinogen more important for it occurence. In this work were described twenty cases of epidermoid carcinoma in bovines that were submited the necropsy in Laboratório de Patologia Veterinária da UFPR - Campus Palotina in period of 1996 to 2007. There was prevalence of animals, breed Holstein middle age of five years, and in the twenty cases, eight showed metastasis. The neoplasms that occur in the eyeball showed metastasis in more of $50 \%$ of the cases mainly to the lungs and regional lymph nodes and when the tumors of the dorsum and of the vulva occurred togheter with neoplasm in eye showed larger metastatic activity. The majority of the epidermoid carcinomas were well-differerentiated and the metastasis probably occurred because of the long time of evolution and excessive infiltration of the tumor in the tissues surrounding.
\end{abstract}

Keywords: Epidermoid Carcinoma, Metastasis, Neoplasms, Bovines.

${ }^{1}$ Acadêmicos do Curso de Medicina Veterinária da UFPR - Campus Palotina. ${ }^{2}$ Laboratório de Histologia e Patologia Veterinária da UFPR Campus Palotina. CORRESPONDÊNCIA: M.B.A.M. Torres [torres@ufpr.br]. 


\section{INTRODUÇÃO}

Os carcinomas epidermóides são tumores malignos das células da camada espinhosa do epitélio. Podem ser também denominados de carcinoma de células espinhosas ou carcinoma espinocelulares, sendo comuns em todas as espécies, principalmente em animais mais velhos [3,4].

Podem aparecer em qualquer parte do corpo, com predomínio em áreas despigmentadas [3,4] sendo a luz solar o estímulo carcinógeno mais importante para estas neoplasias [10].

Em cavalos e bovinos, ocorrem principalmente em junções muco-cutâneas, particularmente pálpebras; em gatos, os locais comuns são a orelha, pálpebra e nariz; nos cães, ocorre mais na cabeça, abdômen, membros posteriores, períneo e dígitos $[3,5]$.

Algumas formas específicas destas neoplasias são o câncer do núcleo do corno e o carcinoma que atinge o globo ocular. O primeiro é uma neoplasia esporádica, que afeta a parte central do epitélio do corno, principalmente em raças zebuínas idosas [7], e o segundo ocorre quando a neoplasia atinge a pálpebra e o globo ocular, popularmente conhecido como "câncer do olho" [4].

Macroscopicamente, os carcinomas de células escamosas podem ser produtivos ou erosivos, e histologicamente, caracterizam-se por cordões de queratinócitos que podem apresentar diferentes graus de queratinização, dependendo se as neoplasias são diferenciadas ou indiferenciadas [5]. Essas neoplasias na pele são descritas como localmente invasivas, causando destruição, embora com baixo potencial metastático [10].

Este trabalho teve como objetivo descrever 20 casos de carcinoma epidermóide em bovinos necropsiados no Laboratório de Patologia Veterinária da UFPR - Campus Palotina, Paraná, no período de 1996 a 2007.

\section{MATERIAIS E MÉTODOS}

Primeiramente, foi feita uma revisão dos protocolos de todas as necropsias de bovinos realizados no Serviço de Patologia Veterinária da UFPR - Campus Palotina, Paraná, de 1996 a 2007. Foram anotados idade, raça, sexo, localização e comportamento biológico das neoplasias quanto à presença de metástases dos casos de carcinoma pidermóide cutâneo na espé- cie bovina. Os materiais provenientes da casuística eram fixados em formol a $10 \%$ e processados pela técnica de Impregnação em Parafina e Coloração de Hema-toxilina e Eosina.

\section{RESULTADOS}

Foram confirmados 20 casos de carcinoma epidermóide com predomínio de ocorrência em animais adultos com uma média de idade estimada de 5 anos; animais da raça Holandesa foram os mais afetados [17] e ainda foi encontrado neoplasia em um animal da raça Nelore, um Gelbvieh e um SRD. Dessas neoplasias foram encontrados 8 casos apresentando metástase.

A localização das neoplasias e a presença de metástase com sua localização está descrita na tabela 1 .

\section{DISCUSSÃO}

Bovinos da Raça Holandesa encontram-se em maior quantidade nas propriedades da região, sendo, assim, mais acometidos por essa neoplasia, que ocorreram preferencialmente nas junções mucocutâneas e em áreas despigmentadas na pele, que são mais sensíveis à incidência dos raios ultravioletas $[3,5]$, os quais são o fator de risco mais importante descrito na literatura.

A grande maioria dos bovinos com neoplasia nessa casuística eram adultos, assim como descrito na literatura [1,4], com exceção de 4 casos com idade inferior a 5 anos.

Embora estes carcinomas de pele sejam considerados localmente invasivos, são descritos apresentando baixo potencial metastático [8], nos 20 casos, foram encontradas metástases em $40 \%$ deles [8 casos]. Especialmente tumores que envolviam o globo ocular, os quais apresentaram metástase em mais de $50 \%$ dos casos principalmente para os pulmões, linfonodos da cabeça (descrito como local inicial de metástases) só foram encontrados em um caso na nossa casuística [2,3].

No caso dos carcinomas de células escamosas do olho, as metástases são descritas como raras e geralmente observadas em animais com tumores grandes, nesses casos, êmbolos de células neoplásicas inicialmente atingem os linfonodos da cabeça antes de alcançarem a circulação sangüínea através do ducto torácico, além dos linfonodos regionais, metásta-ses tem sido observadas nos pulmões, 
Tabela 1. Características dos bovinos com carcinoma epidermóide diagnosticados no Laboratório de Patologia Veterinária da UFPR - Campus Palotina, PR/Brasil, no período de 1996 a 2007.

\begin{tabular}{|c|c|c|c|c|c|}
\hline Casos & Idade & Sexo & Localização da Lesão & Metástases & Raça \\
\hline 1 & Adulta & $\mathrm{F}$ & Vulva, Períneo & Não & HPB \\
\hline 2 & 5 Anos & $\mathrm{F}$ & Pele do Dorso & Não & НРB \\
\hline 3 & Adulta & $\mathrm{F}$ & Pele do Dorso e Vulva & Não & НРB \\
\hline 4 & Adulta & $\mathrm{F}$ & Pele do Dorso e Vulva & Não & НРВ \\
\hline 5 & Adulta & $\mathrm{F}$ & Pele do Dorso & $\begin{array}{l}\text { Linfonodo Subilíaco } \\
\text { Esquerdo. }\end{array}$ & HPB \\
\hline 6 & Adulta & $\mathrm{F}$ & $\begin{array}{l}\text { Pele Abdominal } \\
\text { Lateral Esquerda }\end{array}$ & $\begin{array}{l}\text { Linfonodo Íleofemoral } \\
\text { Esquerdo. }\end{array}$ & HPB \\
\hline 7 & 7 Anos & $\mathrm{F}$ & Olho & $\begin{array}{l}\text { Pulmão, Linfonodo Mediastínicos, } \\
\text { Nervos Craniais e Meninges. }\end{array}$ & HPB \\
\hline 8 & Adulta & $\mathrm{F}$ & Olho & $\begin{array}{l}\text { Pulmão, Pleura, Diafragma e } \\
\text { Linfonodo Mediastínicos. }\end{array}$ & HVB \\
\hline 9 & 3 Anos & $\mathrm{F}$ & Olho e Vulva & $\begin{array}{l}\text { Fígado, Pareotideo Esquerdo e } \\
\text { Linfonodos Mandibulares. }\end{array}$ & НРВ \\
\hline 10 & Adulta & $\mathrm{F}$ & Olho & Não & НРВ \\
\hline 11 & Adulta & $\mathrm{F}$ & Olho & Não & HVB \\
\hline 12 & 13 Anos & $\mathrm{F}$ & Vulva & Não & HPB \\
\hline 13 & 11 Anos & $\mathrm{F}$ & Base do Corno & $\begin{array}{l}\text { Linfonodo } \\
\text { Submandibular. }\end{array}$ & Nelore \\
\hline 14 & Adulta & $\mathrm{F}$ & Olho & Encéfalo e Pulmão. & HPB \\
\hline 15 & 8 Anos & $\mathrm{F}$ & Pele do Dorso & Não & НРВ \\
\hline 16 & 3 Anos & $\mathrm{F}$ & Vulva & Não & SRD \\
\hline 17 & 4 Anos & $\mathrm{F}$ & Vulva & Não & НРB \\
\hline 18 & 8 Anos & $\mathrm{F}$ & Vulva & Não & Gelbvieh \\
\hline 19 & 3 Anos & $\mathrm{F}$ & Olho & Não & HPB \\
\hline 20 & Adulta & $\mathrm{F}$ & $\begin{array}{l}\text { Olho, pele do dorso, } \\
\text { períneo }\end{array}$ & $\begin{array}{l}\text { Linfonodos Retromamários, } \\
\text { Íleofemural e Pulmão. }\end{array}$ & HPB \\
\hline
\end{tabular}

HPB = holandês preto e branco; HVB = holandês vermelho e branco; SRD = Sem raça definida. 


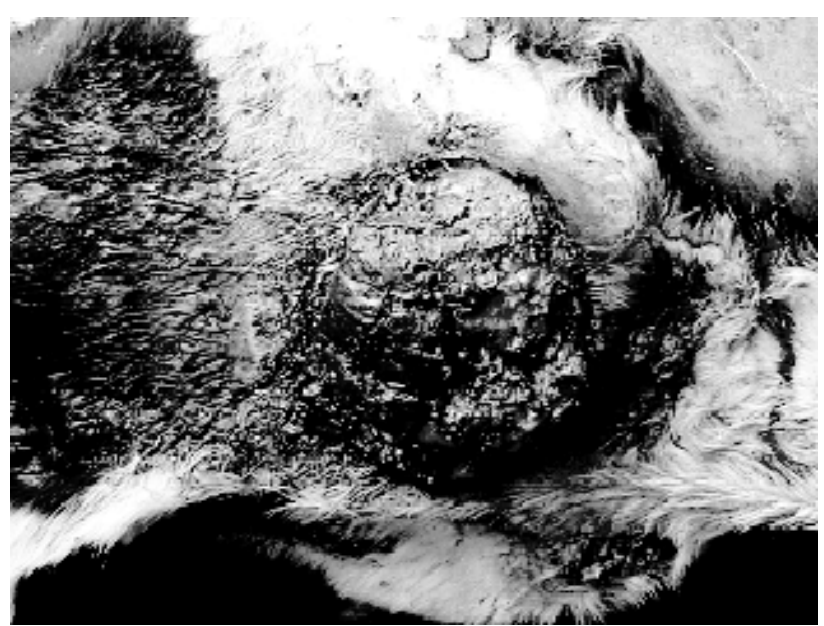

Figura 1. Neoplasia na pele na região dorsal ulcerada em bovino Holandês Preto e Branco.

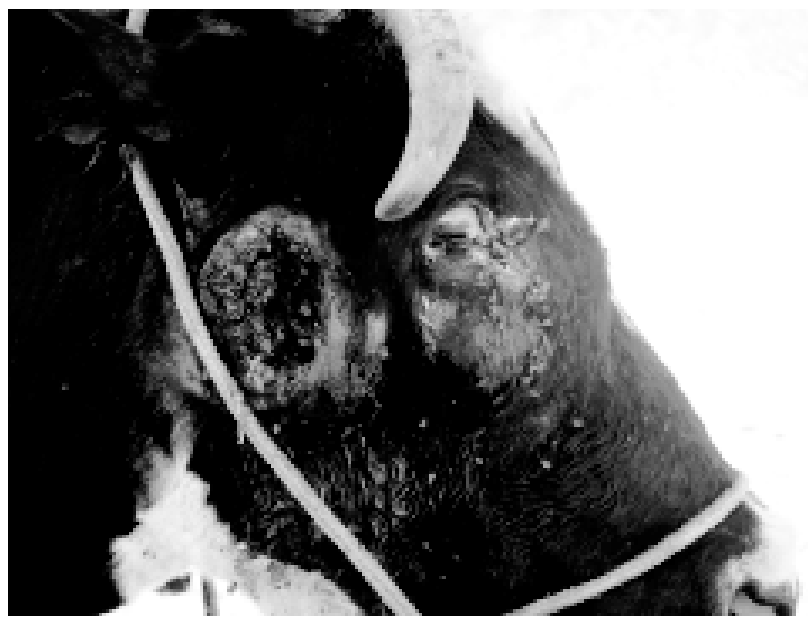

Figura 2. Neoplasia ocular com metástase em linfonodos parotideos em bovino Holandês Preto e Branco.

coração, na pleura no fígado e nos rins [2]. Especificamente no caso 20, a neoplasia era pequena e sem infiltração de linfonodos regionais, porém, havia metástase em pulmão, portanto, essa correlação de tamanho nem sempre é observada com associação de metástase.

No caso da neoplasia do corno, devido à extensão da neoplasia, ocorreu também infiltração da massa na meninge, com compressão do hemisfério telencefálico e estruturas ósseas adjacentes, não sendo encontradas neoplasias intracerebrais, apenas in-filtração de meninge ou nervos cranianos, nestes casos, não se trata de metástase por via hematógena ou linfática, e sim por implantação direta via bainha de nervos cranianos [1]. Além dos carcinomas epidermóides,

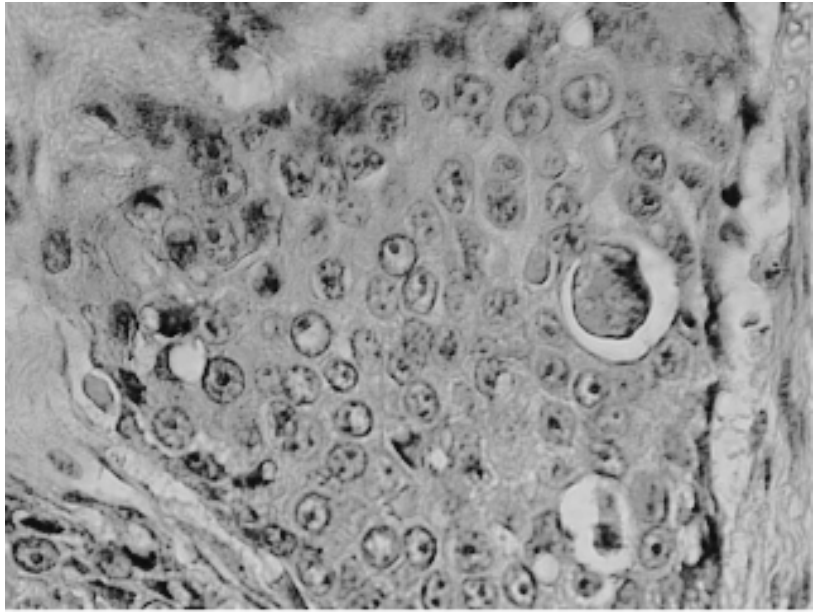

Figura 3. Aspecto microscópico da neoplasia com coleção de células pleomórficas e queratinização individual (HE. Aumento 40X).

outras neoplasias, como os osteossarcomas, condrossarcomas e osteocondrossarcomas multilobulado, podem também infiltrar-se por extensão direta até o sistema nervoso [6].

Dentre as neoplasias que afetaram o dorso, tivemos metástase em apenas um dos casos, ocorrendo em linfonodo pré-crural, e os tumores que acometeram apenas a vulva não apresentaram metástase. Os linfonodos regionais são os principais sítios de metástase dessas neoplasias, principalmente quando trata-se de tumores pobremente diferenciados [3,5]. Quando as neoplasias do dorso e da vulva ocorreram juntamente com o olho, apresentaram maior potencial metastático.

As metástases para os carcinomas epidermóides são descritas como pouco comuns e sendo freqüentemente encontradas em neoplasias pobremente diferenciadas ou que foram diagnosticadas tardiamente [5]. Nos casos analisados, a maioria das neoplasias eram bem diferenciadas e as metástases provavelmente ocorreram devido ao tempo e invasão excessiva do tumor nos tecidos adjacentes.

\section{CONCLUSÕES}

Após estas observações de carcinoma epidermóide é possível concluir que, embora eles sejam descritos na maioria da literatura consultada com baixos índices de metástases, nos casos ora apresentados estes índices aumentaram significativamente quando a neoplasia era excessivamente grande e infiltrativa, especialmente nos tumores que envolviam o globo ocular. 


\section{REFERENCIAS}

1 Barros R.R., Rech R.R., Viott A.M. \& Barros C.S.L. 2006. Carcinoma de células escamosas no olho de bovino com invasão cerebral através dos nervos cranianos. Ciência Rural. 5: 1651-1654.

2 Cordy D.R. 1990. Tumors of nervous system and eye. In: Moulton D.J. (Ed). Tumors of Domestic Animais. 3rd edn. Berkeley: University of California, pp. 640-665.

3 Fava C.D., Veríssimo C.J., Rodrigues C.F.C., Cunha E.A., Ueda M., Maiorka P. C. \& D’Angelino J.L. 2001. Occurrence of squamous cell carcinoma in sheep from a farm in São Paulo state, Brazil. Arquivo do Instituto de Biologia de São Paulo. 1: 35-40.

4 Fernandes C.G. 2007. Neoplasias em ruminantes e eqüinos. In: Riet-Correa, F., Shild A.L., Lemos R.A.A. \& Borges J.R.J. (Eds). Doenças de Ruminantes e Eqüídeos. 3. ed. Santa Maria: Editora Pallotti, pp. 650-656.

5 Goldschmidt M.H. \& Hendrick M.J. 2002. Tumors of the skin and soft tissues In: Meuten D.J. (Ed). Tumors in Domestic Animals. 4th edn. Iowa: Iowa State Press, pp. 45-117.

6 Koester A. \& Higgins R.J. 2002. Tumors of the nervous system. In: Meuten D.J. Tumors in Domestic Animals. 4th edn. Iowa: Iowa State Press, pp. 697-738.

7 Lemos e Nakazato, 2007. Carcinomas de base de chifre. In: Riet-Correa, F., Shild A.L., Lemos R.A.A. \& Borges J.R.J. (Eds). Doenças de Ruminantes e Eqüídeos. 3. ed. Santa Maria: Editora Pallotti, pp. 656-658.

8 Maiolino P., Restucci B., Papparella S. \& Vico G. 2002. Nuclear morphometry in squamous cell carcinomas of canine skin. Journal of Comparative Pathology. 127: 114-117.

9 Pully L.T. \& Stannrd A.A. 1990. Tumors of the skin and soft tissues. In: Moulton J.E. (Ed). Tumors in Domestic Animals. 3rd edn. Berkeley: University of California, pp. 23-87.

10 Yager J.A. \& Scoot D.W. 1993. The skin and appendges. In: Jubb K.V.F, Kennedy P.C. \& Palmer N. (Eds). Pathology of Domestic Animals. 4th edn. San Diego: Academic Press, pp. 531-738. 